\title{
COGNITIVE VS TECHNOLOGICAL MAPS OF GEOSPACE
}

\author{
Vadim Emelin \\ Lomonosov Moscow State University, Russia \\ emelin@mail.ru \\ Alexander Tkhostov \\ Lomonosov Moscow State University, Russia \\ tkhostov@gmail.com
}

This article was supported by the Russian Foundation for the Humanities, project no. 17-06-00849

The formation of cognitive maps of geographical space is a crucial condition for an agent's cognitive activity, determining his possible orientation as the highest psychical function. The initial way of understanding oneself in the surrounding world for humans was to correlate oneself with one's natural dimensionality and to form an anthropomorphic system of measures and coordinates. This article considers processes of transforming natural geography into a culture-determined one, resulting in the formation of world maps based not on the objective vision of geospace but on mythological, religious, pragmatic, and ethnocentric factors. The influence of human's technological extensions on transformation of his natural spatial ideas into cognitive schemata and on change in his spatial "worldview" is analyzed by the example of accessibility/inaccessibility of geographical objects. The paper posits that the possibility to interpret geographical knowledge and skills as symbolic and culture-determined options of the orientation ability are fixed not to natural, but technological mode of travel. Furthermore, the paper describes a special hybrid construct of orientation/locomotion that arises in the conditions of technological progress and sets a new topology of man's cultural body, a technologically transformed topology of the surrounding world. Additionally, it is stated that any technical development does not abolish human dimensionality but only modifies it, expanding natural human abilities and identity.

Keywords: cognitive activity, identity, cognitive map, geography, geospace, technologies, anthropomorphic dimensionality, spatial orientation, transport, embodiment. 


\title{
КОГНИТИВНЫЕ VS ТЕХНОЯОГИЧЕСКИЕ КАРТЫ ГЕОПРОСТРАНСТВА
}

\author{
В. А. Емелин \\ Московский государственный университет имени М. В. Ломоносова, Россия \\ emelin@mail.ru
}

\section{А. Ш. Тхостов}

Московский государственный университет имени М. В. Ломоносова, Россия tkhostov@gmail.com

В статье представлены результаты выполнения проекта РФФИ (№ 17-06-00849)

Статья посвящена теме субъективных представлений о пространстве в форме когнитивных карт. Понятие когнитивных карт достаточно устойчиво существует в психологии и философии, но в данной работе авторы осуществляют достаточно убедительную попытку их интерпретации как социального, технологического и культурно-исторического феномена. Авторы рассматривают культурно-исторические и технологические варианты трансформации пространственных представдений и ориентиров в зависимости от опосредующих средств и делают попытку включения пространственных представлений в контекст культурно-исторического развития. При анализе технологических расширений когнитивных карт особое внимание уделяется их технологическим искажениям и особой роли в построении образа внешнего уделяется и моделям идентификации. Когнитивные карты, таким образом, оказываются вкдюченными в контекст культурно-исторического развития, обогащая, дополняя и развивая саму культурно-историческую концепцию и философию техники.

Ключевые слова: когнитивная деятельность, идентичность, когнитивная карта, география, геопространство, технологии, антропоморфная размерность, пространственная ориентация, транспорт, воплощение.

DOI 10.23951/2312-7899-2018-4-125-141 


\section{Introduction}

Any geography in its initial meaning represents a description of ideas/ knowledge/experience of the earth/space of possible movements. This knowledge is based specifically on sensory human experience of farness or closeness, i.e., any forms of distance, correlation, and position in space and the possibility/impossibility to reach any parts or places. Moreover, from the very beginning, these ideas are not just a totality of neutral knowledge, but a psychological tool of human orientation and the basis for planning possible movements. As soon as humans venture beyond specifically sensory data about the conditions that surround them, they necessarily turn to the "cognitive schemata or maps" described by U. Neisser [Neisser 1976]. "The schema can be likened to a location map with which a traveler checks his road. The presence of cognitive formations that orient an agent's locomotion in relation to reference marks that are actually absent in his visual field belongs to the facts that have been most reliably established in general and comparative psychology" [Velichkovskij 1981, 8]. However, in our opinion, the idea of a specific psychical formation - a cognitive map that underlies locomotor orientation lacks an important link: the possibility to transform it from a natural function into a higher, sign-mediated one. In this sense, the title of E. Tolman's paper is very symbolic: "Cognitive Maps in Rats and Men," which, considering cognitive maps as the basis for orientation, assumes that no principal differences exist between the rat and man [Tolman 1948]. The idea of cognitive maps can be expanded by ideas of the cultural-historical approach to the formation of higher psychical functions based on natural ones under their socialization. In their natural form, cognitive maps are based on the abilities of many animals to orient in space by the sun or the direction of the magnetic field, to use traces of past experience, etc. In man, natural cognitive maps can transform into distinctive, formed-within-lifetime higher functions of orientation in geospace using sign-symbolic tools, primarily geographical maps, thus adding to locomotor capabilities. Here, just like in other higher psychical functions, it is possible to distinguish stages of inter-psychical activity (trained to use maps) and transition from exteriorized tools to interiorized ones. A map materialized as a flat or 3-D (globe) image is an option of an exteriorized embodiment of a cognitive map, when it is visualized, correlated with the model, fitted into the cultural context, etc. Even a verbal map - a story about other lands - is also the exteriorization of experience or knowledge as text. Then it can be interiorized again, becoming 
the basis for a new, no longer natural but culture-mediated mental cognitive map. In this case, it will be acquired knowledge, which man has not obtained from his experience but has assimilated and may well use for his own purposes. Part of the culture-determined map can stay exteriorized as pointers, markers, direction signs, etc.

The novelty of this assumption is in the possibility of the theoretical and practical extension of "higher mental functions" at the expense of embedding culturally- and socially-mediated cognitive maps into them. The possibility of that extension has been in no way restricted by the concepts of "higher functions" formation. A great number of both cognitive and physiological functions have remained beyond limits of the cultural-historical approach. At present, in international investigations the field of "cognitive and behavioral" geography is involved in a number of actively developed trends. There are more than 150 papers mentioned already in the review of 1999 and carried out during the preceding twenty years [Mark et al. 1999]. However, from the theoretical point of view almost all of them are within the limits of the discourse about the variants of cognitive and behavioral spatial skills (skill is the most common term) that do not much differ from Tolman's ideas.

Of special interest is the analysis of the impact of man's technological extensions on the transformation of his cognitive maps and, indirectly, on the change in his "worldview." Although many higher psychical functions can, no doubt, interact in relation to the transformation of natural cognitive maps, they quite unusually intersect with man's technological extension. Man is not only capable of absorbing knowledge, adding to his own cognitive map; he changes natural limitations to his locomotion by inventing transportation means, thus obtaining new knowledge about new capabilities. In other words, by the interaction of sign-mediated cognitive maps and the results of human activity in creating technological transportation facilities, the cognitive map turns into a special hybrid construct of a "locomotion opportunity map," entailing qualitative changes in geography, already fixed not to natural reality but to technological reality.

The purpose of this paper is to analyze changes in cognitive subjective maps of geospace during its sociocultural development and depending on the human use of technological tools. 


\section{Anthropomorphic change in the world}

The initial system of coordinates of natural geography is a correlation of geographical distances with the human body and its natural dimensionality. The human body is a natural system of measures and weights that underlies the ordering and unification of the surrounding reality. Anatomy and physiology are used as models of anthropomorphic dimensionality. The size is measured in inches (the length of the finger phalanx), feet (the length of the human foot), cubits, fathoms (the distance between the outstretched arms), and oblique fathoms (kosaya sazhen, the distance between the outstretched right hand and the big toe of the left foot). The most accepted measure in the ancient world (stadium, first introduced in Babylon) was a distance that man covers at a leisurely pace from the appearance of the first sunbeam at dawn until the entire sun disk rises above the horizon. The Greeks associated this measure with Heracles, equaling a stadium to his 600 steps that he could make from the moment when the first sunbeams appeared above the Hill of Cronus in Olympia until the sun rose above the earth. The mile is a distance of 1000 double Roman steps. In Persia, distance was measured in parasangs (a Persian mile), which is the distance that a caravan travels before the next encampment. The ancient length standard in England was yard, introduced by King Edward in the 10th century. According to the first version, the yard is a distance from the king's nose tip to the end of the fingers of his outstretched hand; and, according to the second version, it is the girth of his wasteline. However, any of these interpretations shows a way of experiencing the chronotope based on the association of a unit of distance and human dimensions (even if the human being was the Lord's Anointed). Analyzing the ideas of space and time of a medieval European man, A. Ya. Gurevich noted that in those conditions it was natural to measure space using the human body, bodily movements, and the ability to affect a matter. The medieval human was physically the "measure of all things," primarily of land, distances, and time [Gurevich 1984, 56-166]). No doubt, the anthropomorphic basis for measuring space was not too accurate; however, it made possible to understand space through human dimensions, e.g., as it was done using the Old Russian palm measurement system.

Human life cycles transformed one way or another into universal units of measurement and organization of space and time: to work till the sweat runs and to walk till you drop. In this connection, Z. Bauman noted that, for the entire human history until the relatively recent 
modern age came, people had measured the world with their bodies: palms, handfuls, or cubits; with objects they had created: buckets or sacks; with the scope of their activity: dividing, e.g., their fields into "morgen," i.e., plots that one man could plow working from dawn until sunset [Bauman 1998]. Any journey has always been restricted by human capacity. Technical development did not transform human dimensionality but only tried to improve it. Pigeon post, which was used to send messages with the maximal possible speed; post stations, where horses were changed; inns and caravansaries; caravan tracks; signal towers, built within sight or reach, - all these represented not so much qualitative but quantitative extensions of the natural chronotope.

Thus, the first methods of exploring space by humans were based on the idea of connectedness of characteristics between the human chronotope and the nature. We are primarily interested in the subjective reflection of geospace as a mental cognitive map: man's subjective idea of his surroundings, built by correlating the real landscape and the capabilities/dimensions of the human body. In a sense, this mental map was initially isomorphic to the real landscape, although, of course, man could be unaware of or could not know certain especially hard-to-reach places (caves, gorges, mountain peaks, etc.). Overall, his mental map, based on real practice or acquired experience, corresponded to reality more or less unambiguously.

\section{Natural and culture-determined geography}

As technology developed and primitive transportation means appeared, man began to expand the capabilities of his body. This marked the initial stage of transformation of isomorphic geography into homomorphic one (the appearance of a trail and then a road makes the previously existing and equal part of the landscape less accessible compared to the roadside one, which also means less existing): so far, these changes commensurate with the human body, and the level of an ambiguous correlation between the mental map and real geography remains relatively insignificant.

Here we deal with the starting point where natural geography transforms into technological one, when, instead of really existing topoi, really accessible topoi come to the forefront. Difficulties generated by the violation of proportion between geographical distances and capabilities of the human body are first manifested not in the principal possibilities 
to reach remote regions but, primarily, in the growing misfit of capabilities to operationally overcome distances incommensurate with the human body, and this, in particular, mainly caused the decline of great empires, such as the Empire of Alexander the Great, the Roman Empire, the Arab Caliphate, the Golden Horde, and the Sublime Porte; they went beyond their technological capabilities to control their territories.

Noteworthy in this respect is an interesting fringe aspect that proves, in our opinion, the principal difference between natural and culturedetermined cognitive maps: the emergence of symbolic detachments or limitations: the Forbidden City in Beijing, Mecca and Medina, the Athos Monastery, the Holy Land, etc. Recall the Berlin Wall, dividing the dwellers of neighboring homes in the same city; frontiers separating Israel and Palestine; the Greek and Turkish Cyprus. The image of the wall creates the essence of artificial space limitations: the desire to introduce certain partitions and obstacles into natural geography to preserve certain identity models by restricting communication, on the one hand, and ensuring security, on the other.

The idea of the "wall" in this case is an "artificial" option of limitations that really exist. Unlike man-made walls, natural objects and conditions became the natural borders of ethnic and cultural spaces. For example, the natural border between France and Spain is the Pyrenees, and the Alps, between Germany and Italy. With slight variations, the Rhine has always served as a natural line dividing catchment areas of France and Germany, and Japan's insularity has remained the main obstacle for the migration of this nation. Recall how long England opposed the construction of the Channel Tunnel, seeing it as a violation of its isolation, uniqueness, and security. Thus, the presence of natural borders became a significant factor in forming stable identities of many nations.

"Artificial" borders are less stably rooted in mental space, and, if not based on a natural foundation, they erode quite easily. In the case of Africa, the violation of its established markers (or because of their absence: there are no borders visible for Europeans in the sand and jungle), using the "ruler and pencil" technology, has led to dismal results. The situation that involves today the peoples of African "backward" countries, who have accidentally found themselves in Europe's chronotope field, can be defined as the "war of all against all," and the absence of a natural basis for symbolic geography is not its least cause. 
The misfit of natural and socio-culturally determined cognitive maps of geospace could be traced by observing discrepancies in dimensionalities, limitations, and special ascribed values of symbolic space. However, the most obvious evidence that culturally and socially mediated ideas of the Earth transform is a real material map as signsymbolic images of geographical space. The clay map from Mesopotamia of the late 8th - early 7th centuries BC, one of the most ancient surviving documents, depicts the world known to Babylonians, showing both real geographical features and mythological elements. In the 2nd century BC, Claudius Ptolemy, considering the Earth's spherical nature, wrote the Geographical Guidance, which, in fact, became a handbook for compiling subsequent geographical maps, although it expectedly contained many errors, especially concerning hard-to-reach territories at that time. Since the American continent was absent on the Ptolemaic map, Christopher Columbus was sure that, to get to India, he had to sail in the western direction.

As Christian worldview consolidated, concepts about the world also changed, and the Hereford Mappa Mundi (Hereford World Map) became their symbol. In line with the theocentric ideology, Jerusalem was in the center of the map. The world was then perceived as flat and round. The map showed with great distortions the main states and the known seas and rivers of Europe and Asia, sitting side by side with mythological and biblical places, such as the Minotaur's Labyrinth, the Land of Gog and Magog, Noah's Ark, and the Garden of Eden. Alongside religious geography, there has always existed fantastic geography, populating places inaccessible for man with dog-headed people, unseen animals, or magicians. The Age of Discovery, associated with the development of maritime transport, brought the outlines of new continents into the world map. The geographical image of the world customary for us was formed by Mercator, a cartographer who proposed an approach to cartography according to which angles and shapes were not distorted and distances were preserved only at the equator. It was named the "Mercator projection." Such mapping turned out to be very convenient for navigation needs. At present this schema is also used to compile navigation maps for seamen and aviators, although it is far from perfect. As M. McLuhan noted, the Mercator projection became a clue to the new vision of the periphery of the rule and wealth [McLuhan 1962]. Arno Peters, a famous fighter against Eurocentrism in the 20th century, created a world map (the Peters World Map) in 1973 that reflected the Earth's surface without distortion. As a result, characteristically selfevident geographical concepts turned out to be discredited. Europe, 
centrally positioned on the Mercator map, deflated and moved to the north; the African and South American continents got stretched and enlarged in size. India's area did not look smaller any more than Greenland or Scandinavia; Russia's size did not appear larger than Africa, and the tiny countries of Europe did not have areas larger than the entirety of South America. Thus, the Mercator map, a technologically convenient tool for moving across the planet, has turned into an effective mechanism of forming a specific worldview, where the Northern Hemisphere (no wonder, it is located atop) dominates the Southern Hemisphere and is deliberately enlarged in size to highlight the role of Northwest.

\section{Technological measurement of the accessibility of geographical features}

While natural, mythological, religious, and pragmatic factors initially played a decisive role in drawing cognitive maps of geospace, technological aspects come to the forefront today. In addition, an interesting and meaningful transformation occurs: isomorphic geography, based on the capabilities and dimensionalities of the human body, transposes toward constantly growing homomorphism.

The first step in this direction is the development of the primary element of cartography, the road, since right from the start the road transfers the dimensionality of corporal accessibility into the dimensionality of technological accessibility. The gradual and parallel complication of road networks and vehicles that use them, from wagons to TGV expresses, forms a very specific geography, which is practically incomparable with man's corporal capacities. The map is replaced with a schema, and the distance itself stops being the most meaningful, since technological capabilities practically even it up, giving way to communication hubs, transfer alternatives, and accessibilities. An example of the most in-demand maps of the technologically transformed world is a metro scheme at the level of a megalopolis, a network of rail and motor roads at the level of a country, and points of airports and lines of air routes that connect them at the planetary level.

The very fact of the chronotope's technological transformation has been discussed more than once in modern sciences about society and man: in variants of social, economic, transportation, and other geographies (see [Simmel 1995; Giddens 2001; Bourdieu 1987; Filippov 2008; Smotrickij 2008; Kasavin 2001; Antonovskij 2011]). However, 
beyond this discussion, as a rule, was the question how a spatiotemporal transformation itself changes "psychological geography," a subjective worldview, man's idea of distance, accessibility, boundaries, possibilities and ways of its identification in the conditions of growing changes in technological communications. The transformation of natural geography into technological one is the translation of the real into the accessible. In addition, the previously inaccessible possibilities of reflecting the real, unsupported by capabilities and the necessity to reach it, increasingly tear natural geography away from a technological one: state-of-the-art google maps can reflect more or less accurately practically all existing points of geographical space, but the maps of roads and transportation remain the real technological map.

Let us run a mental experiment: we return man into the initial (natural) situation by hypothetically amputating all the extensions that he has acquired during social and technological evolution: roads, horses, ruts, wheels, ships, trains, automobiles, airplanes, and airports ... As a result, we will get a natural man limited by the functional capabilities of his natural body and his ideas of the surrounding world based on them. We will see a sharp curtailing of the chronotope and the turning of the technological geographical map into a mythological one. In case of a real inaccessibility and un-verifiability, natural geography is not different from the ideas of medieval dreamers of Prester John's kingdom or the map of Middle-earth, the land of Hobbits, elves, dwarfs, and humans.

Describing historical collisions that violate the limits of geography, we pursue the goal of turning back to the present. Today, the relationship between the body and territory, distance and time, a map and locality can be questioned theoretically. The state-of-the-art transport technologies have changed the scale of the chronotope and have cardinally transformed natural geography. Thanks to the industry of air transport, man became able to cover long distances within a relatively short time. Several centuries have passed since the legendary caravels La Pinta, La Niña, and La Santa María, but, like in the Spanish Empire, in modern information society, transport communication is an unfailing condition of economic prosperity. Speed has changed radically. While the path of Columbus to Haiti took about three weeks, today it takes 14 hours to fly from Moscow to the Dominican Republic. Airports have become the main indicators of accessibility and development of a place. If we look at the route map of a large airline, we will see the true map of the world. The rest of the space of the physical map of the world, away from points of destination, becomes an inaccessible blank spot. 
In our opinion, the emergence of the "worldwide" lifestyle is directly associated with the leap and bounds of technological development of communication means over the last decades of the past century and at the beginning of the current century. First, these changes are associated with the development of aviation and high-speed railroad network, as well as with the constant improvement of their rising comforts. M. McLuhan noted that the road is used increasingly seldom for moving and increasingly more often for leisure. The contemporary traveler stops experiencing the very act of traveling. For example, an ocean liner can well qualify for a hotel in a big city, and an air traveler, regardless of whether he/she flies over New York or Tokyo, in terms of experiencing the road itself, could well be in a cocktail hall. He starts traveling only after he lands [McLuhan 1964]. Transport has become not only a delivery vehicle from one place to another but also a subject of tourism as such.

At the same time, the improvement of transport facilities is not the only cause of the avalanche-like growth of human transits across the world. A whole range of services that make traveling increasingly affordable formed in the past decade. Noncash remote banking technologies using credit cards and the creation of specialized web sites for booking hotels, air, or railroad tickets have changed the map of the world, making it detailed and accessible to the maximum. Information technologies transformed natural geography, turning the world into a "global village." Without leaving home, one can compile a map of one's journey, buy tickets, choose the place of lodging, obtain information about sights, excursions, museums, restaurants, and so on. Traveling has become easy and accessible in information society. Booking.com, an Internet-based service of hotel booking, attracts over 20 million visitors a month. However, what remains unchanged is that the existence of a tourist attraction depends not on its actual reality but on the possibility to be included into technological chains of the tourist business converged with transport routes.

The idea of commensurability between distance and man remains topical; however, the development of transit capacities modified the spatial dimension of distance into the temporal one. Technology subordinated the map to the schedule, having created a specific chronoscope of departure, pegged to time. It is hard to imagine for a person what is 10,000 miles, but it is quite possible for him/her to imagine what a fiveday journey or 80 days underwater are. The question "How far is it from Moscow to Paris?" will hardly be answered by anyone, "2,865 km." Most probably, we will hear, "3.5 hours by plane." 
E. Giddens noted that social geographers proposed a useful and exciting concept of spatiotemporal convergence to analyze how social development and technological changes affect forms of social activity. So, within this approach, as transport systems improve, distances "shrink" [Giddens, 2001]. For example, the travel time from the eastern to the western coast of the United States can be estimated depending on the measurement of the transportation speed. On foot, this journey takes over two years; on horseback, eight months; in a stagecoach, four months; by railroad in 1910, four days; by car today, two and a half days; by a regular air flight, four hours; by a high-speed jet plane, slightly over two hours; and by a space shuttle, a few minutes [Janelle 1968]. True, for a person who refuses to travel because of no motivation and financial possibilities, the distance between Moscow and Paris becomes infinite. The extension of the world has the opposite side, since it can be accompanied by the depletion of topoi that are close, customary, or unmarked on the information map. Following this way, the world can turn into a peculiar map from a glossy magazine: 1,000 places you must see before you die.

The true measure of the geospace of the contemporary world depends on technologies: cells of mobile communications, the wireless Internet, ATMs, transport thoroughfares, and gas-filling stations, - these are the true criteria of man's belonging to the geography of an information society. The contemporary world, characterized by M. Castells as the "Internet Galaxy," forms new maps, in which nodes and thoroughfares that organize the Internet traffic become the main points. Internet geography, or cyber-geography, emerges, where the central place is occupied by one who has the most powerful infrastructure, throughput capacity, and, respectively, the density of territorial coverage by a network. From this point of view, like Europe on the Mercator map, the United States occupies the central place in the Internet Galaxy, playing the main role in communication between other countries. It often happens that communications between two European or Asian (to say nothing of African or Latin American) cities is initially done through an American node [Castells 2001].

\section{Traps of modern navigation systems}

The arrangement of a city changes the topology of human travel in it. In ancient poleis and medieval cities, because of their small sizes, man did not require any additional means for internal movements, every- 
thing was within a walking distance. In a present-day megalopolis, the topology represents a techno-morphic system. Noticeable is the difference between space perception depending on transportation system type: the subway, ground public transport, automobile, or walking on foot. In the first two cases, the city topology for man will be rigidly tied to the reality of existing transport networks with their points of transfer, the length of marches, the arrangements of exits, current and capital repairs, and so on. A motorist is limited by the availability, efficiency, and accessibility of roads themselves; the knowledge of the road network and traffic conditions; and holding meetings, marches, and parades, while a pedestrian, only by the capabilities of his/her body. There is no single map: there are maps for pedestrians, cyclists, drivers, taxi drivers, long-haul drivers, bureaucrats, and the disabled. For the latter, however, there can exist no map at all that is associated with their physical capacity: in the limiting case, constrained by the size of the bed. Successful transit in the system of rapid public transport (metro, express streetcars, monorail systems, and commuter trains) requires the presence and understanding of the scheme of this system, which, in fact, predetermines the possibility of reaching a certain point. In the case with ground transits - by automobile or on foot - the navigator mitigates and sometimes aggravates the situation. The navigator's successful operation is based on the closest correspondence of the ground map entered into the actual state of affairs. Interestingly, the GPS system transforms homomorphic geography back into isomorphic one, reflecting the real scale of distances but still being limited by transport accessibility in most cases. In addition, an area sketch loaded into a gadget remains to be tracing paper without regular and opportune updates. However, urban geography is neither invariable tracing paper nor a transfer picture. It is a constantly changing rhizome map with moribund and emerging road shoots. The point is that on the road, not every shortcut turns out to be the quickest but that, blindly trusting an instrument, people lose the ability to orient themselves with respect to the terrain, simultaneously losing the fear of unknown space, once crucial for survival.

The finite embodiment of transformation of natural geography has happened due to technological improvements that ultimately exteriorize the map, for example, using the GPS system. This is an unconditional extension of man, but here, as in the case mentioned by Plato, who thought that the writing system replaced the memory, the map can replace the ability of spatial orientation. "If men learn this [writing], it will implant forgetfulness in their souls; they will cease to exercise 
memory because they rely on that which is written, calling things to remembrance no longer from within themselves, but by means of external marks" [Plato 1993, 186]. Let us replace the word writing with GPS, and we will interpret Socrates' parable in a different context.

While an indicator, like a map, embodied on the ground, still implies elements of internal orientation, in the case with GPS, we face a rare option of an extended individual who hands over his/her orientation capabilities to a technological system. Possibly, this is one of the first implementations of the idea of transhumanists of the creation of hybrid cyborgs, since human activity in this case is only limited to the choice of direction and the necessity to follow GPS indications. While Plato's position in the memory-to-writing ratio remains disputable, in the current situation we should probably admit that he is right. An interesting substitution and a simplification of orientation activity take place: man can, in principle, avoid the necessity to interiorize any map, except for the GPS manual, which saves him the trouble of learning geography or being able to read maps.

\section{Conclusions}

Transformation of natural geography is not reduced to simple technological changes. These changes are complicated human extensions that set, on the one hand, a new topology of the cultural human body and, on the other, the equally changed topology of the surrounding world. This world, although remaining, no doubt, real, stops corresponding accurately to the actual landscape, turning into a comfortable, accurate transit scheme, which reveals right away its bankruptcy beyond those technological conditions for which it was created. However, within the preset framework, it is quite effective, as is effective the Etak map, described by U. Neisser, which Polynesians use for orientation in an open marine space [Neisser 1976]. This map is not tied to the natural landscape; it is a synthetic derivative of the perception of the stream, the sun position, and the direction of the flight of birds.

Transformation of natural geography, which started from the very first steps of man toward instrumental mediation of the possibility of transit, changed simultaneously his ideas of the surrounding world and identity in general. Each technological reclamation of the external world creates its own adaptive cognitive map, associated with the real landscape, depending on the level of technological development and possessing various degrees of freedom. Nevertheless, the space 
adaptation mechanism, both in primitive man and in a passenger of an intercontinental liner, is still the ability to form cognitive maps, which equilibrate man's natural capacity to move, and cognize space and the scale of "vastness" which he strives to cover. Cognitive mapping is an ancient mechanism of discovering the world by anthropomorphizing and adjusting it to the human self, and the reclaimed world tends to be perceived as something due, as something of its own [Bourdieu 1987].

Modern transport technologies, in their perfection, as well as in their sensitivity, build the geography of our world in a special way. Today, the accessibility of these geographical features is not determined simply by distance in kilometers but is built as a cognitive schema, e.g., based on the possibility and convenience of obtaining it or personal motivation of visiting it. Despite the existing reference measures and weights, humans still feel more comfortable using a system commensurate of their bodies and understanding of possible accessibility. The reference meter is kept in an air-free chamber at the International Bureau of Weights and Measures in Paris, but in everyday life, we measure the size of a room by eye or by wide steps (anthropomorphic meters), and distance, by the human capacity of covering it. The formation of mental maps, as before, remains both a condition for geospace cognition and a mechanism of human adaptation to new conditions, granted by modern transport and information technologies. Technical development does not change the anthropomorphic measurement of geospace but just modifies it, extending natural human capacity. Sitting in an armchair of a TGV express, speeding at $300 \mathrm{~km} / \mathrm{h}$, and planning on a touchscreen of his tablet computer his world map "for tomorrow," a traveler in an information society continues to ask the same question, just like his not-so-distant ancestor, riding on horseback to an inn, "How much time to go?"

\section{REFERENCES}

Antonovskij 2011 - Antonovskij A. Yu. Socioepistemologiya. O prostranstvenno-vremennykh i lichnostno-kollektivnykh izmereniyakh kommunikatsii [Socioepistemology: On Spatiotemporal and Personal-Collective Measurements of Communication]. Moscow: Kanon, 2011, p. 300 (In Russian).

Bauman 1998 - Bauman Z. Globalization: The Human Consequences. New York: Columbia University Press, 1998. 136 pp. 
Bourdieu 1987 - Bourdieu P. "Espace social et pouvoir symbolique," in: Bourdieu, P. Les choises dites. Paris: Éditions de Minuit, 1987, pp. 47-66.

Castells 2001 - Castells M. The Internet Galaxy. Reflections on the Internet, Business and Society. Oxford University Press, 2001. 304 pp.

Filippov 2008 - Filippov A. F. Sociologiya prostranstva [Sociology of Space]. St. Petersburg: Vladimir Dal', 2008, 285 pp. (In Russian).

Giddens 2001 - Giddens A. Sociology. Cambridge: Polity Press, 2001, $768 \mathrm{pp}$.

Gurevich 1984 - Gurevich A. Ya. "Predstavleniya srednevekovogo evropeitsa o prostranstve i vremeni" [The ideas of a medieval European of space and time], in: Gurevich, A. Ya. Kategorii srednevekovoi kul'tury [Categories of Medieval Culture]. Moscow: Nauka, 1984, pp. 56-166 (In Russian).

Janelle 1968 - Janelle D. G. "Central place development in a time-space framework," Professional Geographer, 1968, Vol. 20, pp. 5-10.

Mark D. M. et al. 1999 - Mark D. M., Freksa C., Hirtle S. C., Lloyd R., Tversky B. Cognitive models of geographical space. Int. J. Geographical Information Science. 1999. Vol. 13. No. 8, 747-774 pp.

McLuhan 1962 - McLuhan M. The Gutenberg Galaxy: The Making of Typographic Man. Toronto: University of Toronto Press, 1962, 293 pp. McLuhan 1964 - McLuhan M. Understanding Media: The Extensions of Man. New York: McGraw Hill, 1964, 359 pp.

Neisser 1976 - Neisser U. Cognition and Reality: Principles and Implications of Cognitive Psychology. New York: Freeman, 1976, 230 pp.

Plato 1993 - Plato. Sobranie sochinenii v 4 tomakh [Collection of Works in 4 Vols.]. Vol. 2. Moscow: Mysl', 1993. (In Russian).

Simmel 1995 - Simmel G. "Soziologie des Raumes," in: Georg Simmel Gesamtausgabe. Vol. 7, Ed. by Rüdiger Kramme, Angela Rammstedt, and Otthein Rammstedt. Frankfurt am Main: Suhrkamp, 1995, pp. 132-183.

Smotrickij 2008 - Smotrickij E. Yu. "Transport: opyt filosofskoi refleksii” [Transport: An attempt of philosophical reflection], Relga, 2008, № 11 (http://www.relga.ru/Environ/WebObjects/tgu-www.woa/wa/Main? textid=2221\&level1=main\&level2=articles) (In Russian).

Tolman 1948 - Tolman E. "Cognitive maps in rats and men," Psychological Review, 1948, Vol. 55, no. 4, pp. 189-208.

Kasavin 2001 - Uranos i kronos. Khronotop chelovecheskogo mira [Uranos and Chronos: The Chronotope of the Human World], Ed. by Kasavin I. T. Moscow: RT Press, 2001 (In Russian). 
Velichkovskij 1981 - Velichkovskij B. M. “Vstupitel'naya stat'ya k knige U. Naissera 'Poznanie i real'nost'” [Introductory article to U. Neisser's book Cognition and Reality] in: Naisser, U. Poznanie i real'nost' [Cognition and Reality]. Moscow: Progress, 1981, pp. 5-15 (In Russian).

Материал поступил в редакцьию 07.09.2018 